EPJ Web of Conferences 92,02085 (2015)

DOI: $10.1051 /$ epjconf/ 20159202085

(C) Owned by the authors, published by EDP Sciences, 2015

\title{
Numerical and experimental investigation of swirling flow in a conical diffuser
}

\author{
Štefan David ${ }^{1, a}, Z_{\text {Zubík Pavel}}^{2}$, Hudec Martin ${ }^{1}$ and Rudolf Pavel ${ }^{1}$ \\ ${ }^{1}$ Brno University of Technology, Faculty of Mechanical Engineering, Technická 2896/2, 616 69, Brno, Czech Republic \\ ${ }^{2}$ Brno University of Technology, Faculty of Civil Engineering, Veveří 331/95, 602 00, Brno, Czech Republic
}

\begin{abstract}
The decelerated swirling flow often breaks down into helical structure which is unstable and causes unsteady velocity and pressure fields. The numerical and experimental investigation of this flow pattern is carried out on the experimental apparatus consisting of the swirl generator (producing a strong swirling flow) and the transparent conical diffuser (where the helical structure can be observed). The open source CFD software OpenFOAM employing realizable k-epsilon turbulence model is used for the numerical simulations. The experimental measurements are focused on LDA measurements of velocity profiles in the diffuser crosssections. Agreements between numerical end experimental results are discussed.
\end{abstract}

\section{Introduction}

In many cases of industrial fluid flows the flow instability called vortex breakdown occurs as a consequence of mechanisms in decelerated swirling flow. The vortex breakdown can be found in several forms related to the character of particular flow. Nevertheless, many forms of vortex breakdown are not relevant to industrial applications, e.g. bubble form of vortex breakdown in low-Re flows. In case of hydraulic turbines with constant pitch of the runner (e.g. Francis turbine), the high Reynolds number spiral form of the vortex breakdown (called vortex rope) appears, when the turbine is operated at part load, see figure 1 .

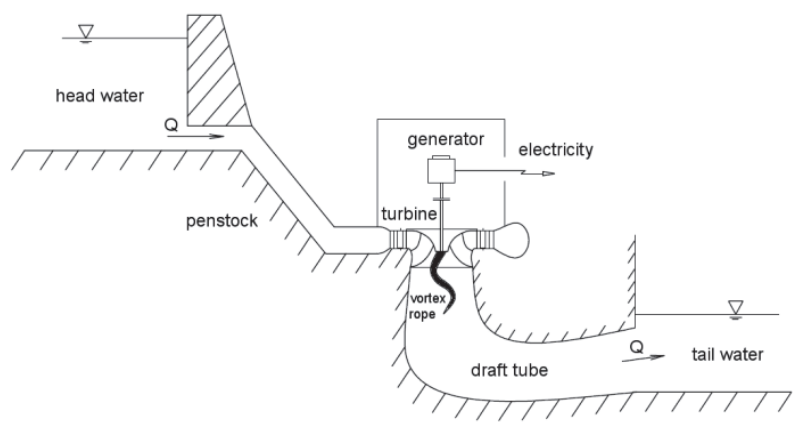

Figure 1. Vortex rope in turbine draft tube

The mechanism of the spiral breakdown is described as a rapid axial deceleration towards what appears to be a stagnation point. Then the straight swirl expands outwards into helix and after one or two windings of the spiral, the filament breaks up in large scale unsteadiness and turbulence [1]. The spiral is the basic form of the breakdown [2].

Even the large database [3], covering investigations of the vortex breakdown during the last forty five years and extensive theoretical, experimental and computational research, we still lack deeper understanding of all influences on origin of this phenomena and their relations to the vortex rope properties (frequency of the precessing motion, helix shape, pressure amplitudes, etc.) [4]. Some important features of the vortex breakdown related to the flow in the draft tube can be mentioned; the vortex breakdown is asymmetric and time dependent, precessing vortex core is developed and laid on the boundary of main flow and recirculation region [3]. The spiral form of the vortex breakdown can be interpreted as a nonlinear global mode originating at the convective/absolute instability transition point of the axisymmetrical vortex breakdown bubble $[5,6]$.

Susan-Resiga et al. [7] concluded that the most significant case of the vortex breakdown in conical diffusers is a high Re spiral shape with central quasi stagnant region. They concluded, that the vortex breakdown in conical diffusers is a mechanism for limiting the increase in the swirl number

$$
S_{n}=\frac{\int v_{a x} v_{t a n} r d S}{R \int v_{a x}^{2} d S}
$$

and it occurs once the inlet flux of circumferential momentum is large enough with respect to the flux of axial momentum.

In order to study mechanism of the spiral vortex breakdown in simplified conditions, the experimental

$\overline{{ }^{a} \text { Corresponding author: david.steffan } @ g m a i l . c o m}$ 
apparatus of swirl generator was developed. In section 2 the experimental measurements are discussed following by numerical study presented in section 3 .

\section{Experimental measurements}

The swirl generator apparatus is built in the experimental test rig with a gravity driven flow rate. The swirl generator apparatus consists of 9 blades which create swirling component of the flow entering the connected transparent diffuser with cone angle of $12 \mathrm{deg}$. The diffuser is made from a plexiglass to ensure penetration of laser beam for the LDA measurements and with five holes along the cone length where the pressure transducers are mounted. The blades of swirl generator are designed so that the leading edge lays in the axial direction of the flow and the trailing edge goes from 30 deg (on the spike side) to $50 \mathrm{deg}$ (on the shroud side) deflection. The scheme of the swirl generator is shown in figure 2 .

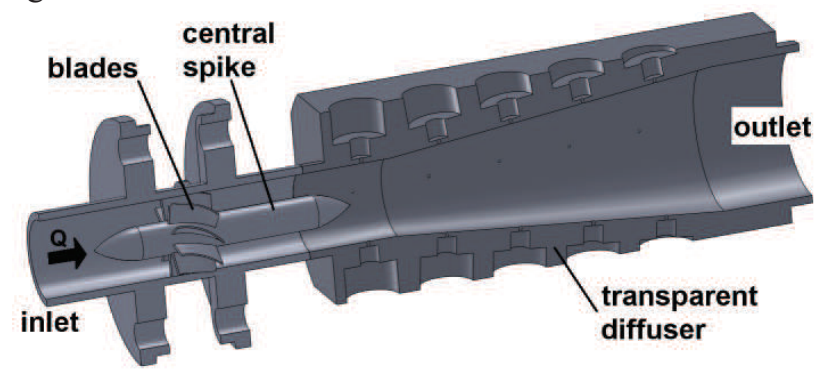

Figure 2. Scheme of swirl generator apparatus.

The upper tank of the test rig is supplied by the hydraulic pump from the lower tank and simultaneously supplies the main pipeline system where the swirl generator apparatus is situated. The pipeline system continues from the swirl generator apparatus and ends in the lower tank. The flow rate is driven by the valve situated in sufficient distance from the diffuser outlet. The simplified scheme of the experimental test rig is shown in figure 3.

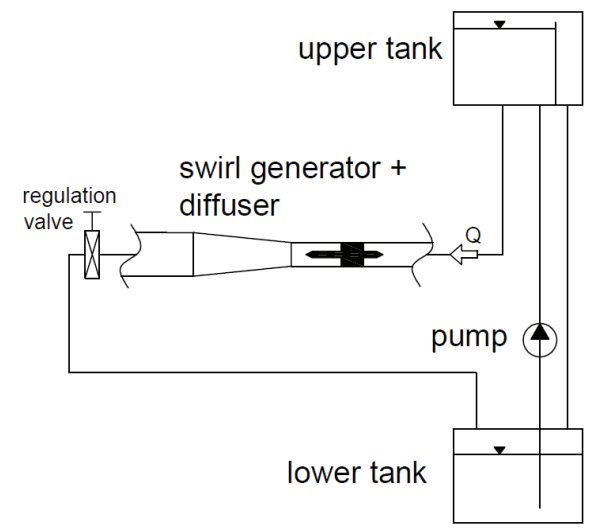

Figure 3. Scheme of experimental test rig.

When the flow rate is sufficiently large the low pressure in vortex core cause cavitation and spiral shape of vortex structure become visible. In figure 4 the picture of vortex structure captured by high-speed camera is presented for flow rate $\mathrm{Q}=13.5 \mathrm{l} / \mathrm{s}$.

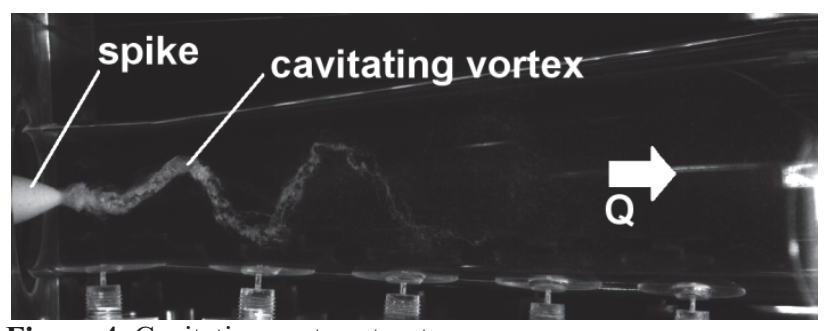

Figure 4. Cavitating vortex structure.

\subsection{LDA measurements of velocity}

The LDA measurements were performed in three crosssections through the diffuser cone for flow rates ensuring non-cavitation regime. The axial and tangential velocities were measured simultaneously starting $2 \mathrm{~mm}$ from the diffuser cone wall and going perpendicularly to the diffuser axis with the $2 \mathrm{~mm}$ step for the axial velocity. The measuring step for tangential velocity is different due to curvature of the diffuser cone causing different refraction of the laser beams for each new probe location. The laser probe size is approximately $2 \mathrm{~mm}$ long and $0.75 \mathrm{~mm}$ wide. The argon-ion laser producing three most powerful colours from light spectra (blue, green, violet) is used. The laser beams are separated through the optical passage with colour filters and divided into four (two for axial and two for tangential velocity) laser beams, see figure 5 .

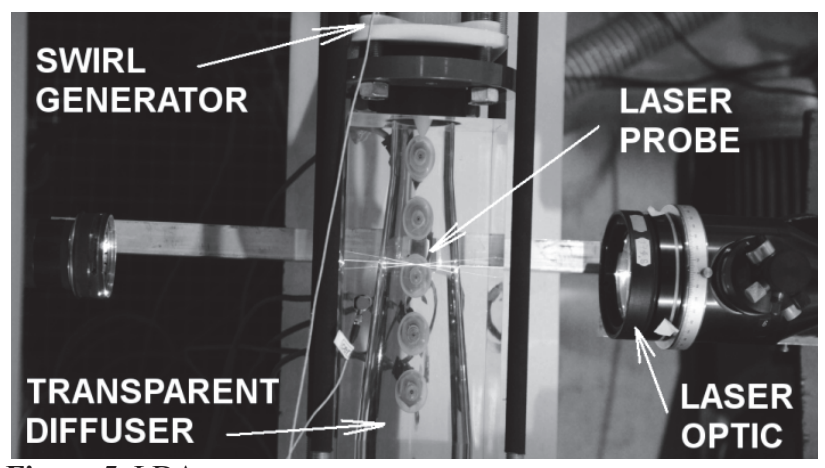

Figure 5. LDA measurements.

The velocity measurements were carried out in three locations $\mathrm{S} 1=23 \mathrm{~mm}, \mathrm{~S} 2=50 \mathrm{~mm}$ and $\mathrm{S} 3=75 \mathrm{~mm}$ from the beginning of diffuser cone, see figure 6 . The measured flow rates are $\mathrm{Q}=5,7,8$ and $11 \mathrm{l} / \mathrm{s}$.

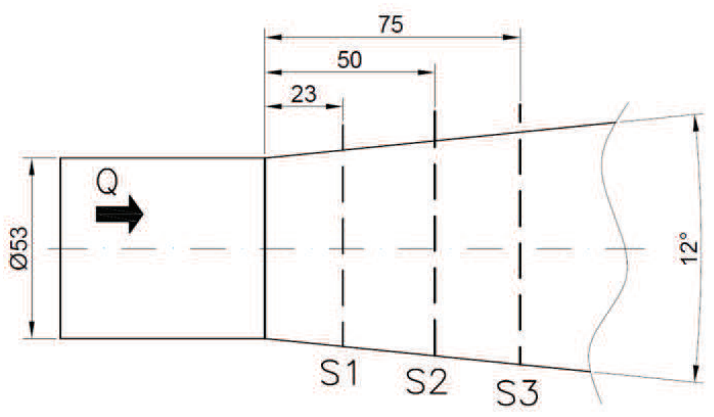

Figure 6. Locations of LDA measurements. 
In figure 7 the measured axial and tangential velocity profiles in S2 cross-section are plotted for measured flow rates.

One can see that magnitude of axial and tangential velocity is almost unchanged in central region when the flow rate increases. The main flow is realized close to the diffuser wall. This is typical for flows where the spiral vortex structure is developed.

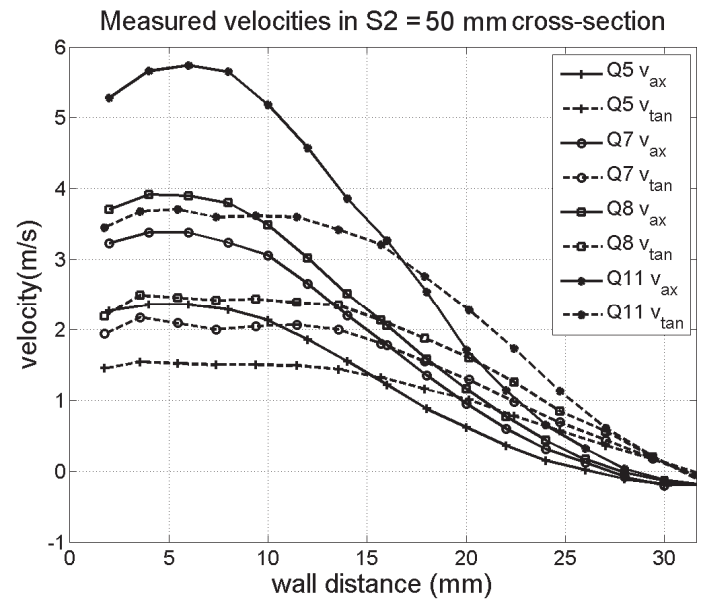

Figure 7. Profiles of axial (solid lines) and tangential (dashed lines) velocities in the diffuser cross-section of $95 \mathrm{~mm}$.

\subsection{Unsteady pressure pulsations}

In order to estimate rotating frequency of the vortex structure the pressure transducer situated at the beginning of the diffuser cone is used. The amplitude-frequency analysis is carried out using standard FFT function in MATLAB software. The frequency spectra for flow rate $\mathrm{Q}=7 \mathrm{l} / \mathrm{s}$ is shown in figure 8 . One can see that two dominant frequency peeks occur. From our analysis and visual observations was found that the vortex structure is not perfectly coherent in time. The fully developed spiral shape gradually decays and arises again. Thus the higher frequency corresponds to rotating movement of the vortex and lower frequency is consequence of decaying process.

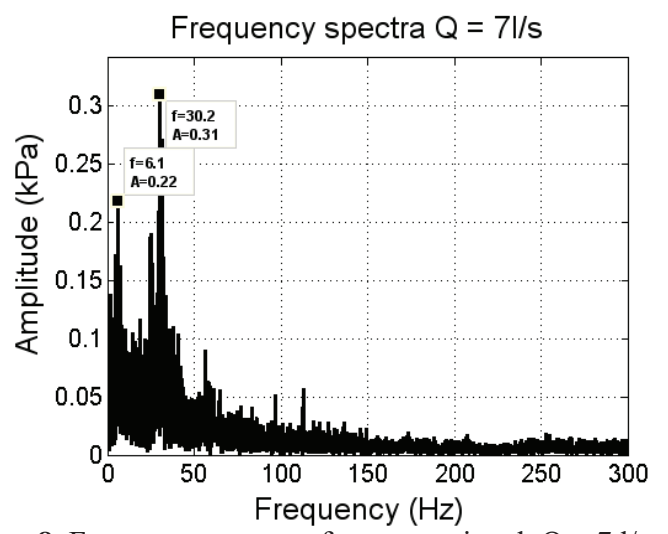

Figure 8. Frequency spectra of pressure signal, $Q=71 / s$.

In table 1 the rotting frequencies for measured flow rates are summarized. It is obvious that the rotating frequency of the vortex structure increases linearly when the flow rate increases.
Table 1. Rotating frequencies of vortex structure.

\begin{tabular}{|c|c|}
\hline Flow Rate (1/s) & $\mathbf{f}(\mathbf{H z})$ \\
\hline 5 & 22.1 \\
\hline 7 & 30.2 \\
\hline 8 & 32.3 \\
\hline 11 & 48.4 \\
\hline
\end{tabular}

\section{CFD computations}

The CFD analysis is carried out using open-source software OpenFOAM in version 2.2.2 on the mesh consisting of 4009020 hexahedral and tetrahedral cells. The tetrahedral cells are used only in the spikes regions. The computational domain shown in the figure 9 covers main part of the swirl generator apparatus.

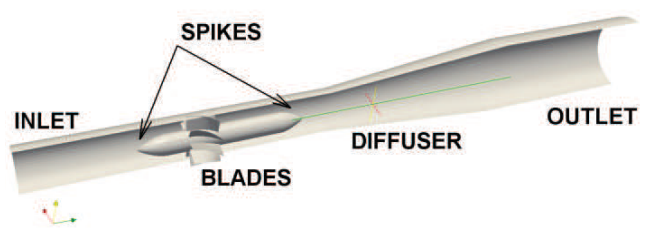

Figure 9. Computational domain of swirl generator apparatus.

The Realizable k-epsilon turbulence model is used and velocity inlet with pressure outlet is prescribed for boundary conditions. The overview of numerical case setup is summarized in table 2 .

Table 2. Case set-up of numerical computation.

\begin{tabular}{|c|c|}
\hline Turbulence Model & Realizable k-epsilon \\
\hline $\begin{array}{l}\text { Near-Wall } \\
\text { Treatment [8] }\end{array}$ & $\begin{array}{l}\text { High Re wall function for } \\
\text { k-epsilon }\end{array}$ \\
\hline $\begin{array}{l}\text { Pressure-Velocity } \\
\text { Coupling }\end{array}$ & PIMPLE \\
\hline \multicolumn{2}{|c|}{ Discretization schemes } \\
\hline Time & Second order \\
\hline Gradients & Second order \\
\hline Vector fields & Limited linear differencing \\
\hline Laplacian schemes & $\begin{array}{l}\text { Unbounded, second order, } \\
\text { conservative }\end{array}$ \\
\hline Interpolations & Linear \\
\hline $\begin{array}{r}\begin{array}{r}\text { Surface normal } \\
\text { gradients }\end{array} \\
\end{array}$ & Explicit non-orthogonal correction \\
\hline \multicolumn{2}{|l|}{$\begin{array}{l}\text { Boundary } \\
\text { conditions }\end{array}$} \\
\hline Inlet & $\begin{array}{l}\text { Velocity inlet with fixed velocity } \\
\text { magnitude } \\
\text { Values of } k \text { and epsilon correspond } \\
\text { to } 5 \% \text { of turbulence intensity }\end{array}$ \\
\hline Outlet & $\begin{array}{l}\text { Pressure outlet with fixed value of } \\
\text { kinematic pressure } p / \rho=0\end{array}$ \\
\hline $\begin{array}{l}\text { Time-step Size } \\
(\mathrm{Co}=3)\end{array}$ & $\begin{array}{l}1.5 \mathrm{e}-5 \mathrm{~s}(\mathrm{Q}=71 / \mathrm{s}) \\
2.3 \mathrm{e}-5 \mathrm{~s}(\mathrm{Q}=51 / \mathrm{s})\end{array}$ \\
\hline
\end{tabular}

The simulations are carried out for flow rates correspond to experiment. The each simulation decomposed into 32 processor domains run employing pimpleFoam solver until periodic state and then the time averaged values of the velocity and pressure were recorded. In figure 10 is shown instantaneous snapshot of vortex core. 


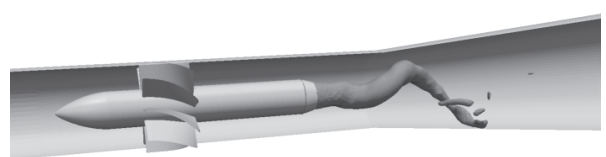

Figure 10. Vortex structure visualised by iso-surface of static pressure for flow rate $\mathrm{Q}=7 \mathrm{l} / \mathrm{s}$.

The computed time-averaged velocities are extracted using sample utility through the line corresponding to the measured locations S1, S2 and S3. The comparison of computed and measured velocity profiles in corresponding crsoss-sections is plotted in figures 11.-13. for $\mathrm{Q}=5 \mathrm{l} / \mathrm{s}$ and in figures 14.-16. for $\mathrm{Q}=7 \mathrm{l} / \mathrm{s}$. The variation of Random Mean Square Velocity ( $\mathrm{u}_{\mathrm{RMS}}$ ) for each measured point is presented in form of error bars. $\mathrm{U}_{\mathrm{RMS}}$ was calculated using following equation:

$$
u_{R M S}=\sqrt{\sum_{i=0}^{N-1} \frac{1}{N}\left(u_{i}-\bar{u}\right)^{2}}
$$

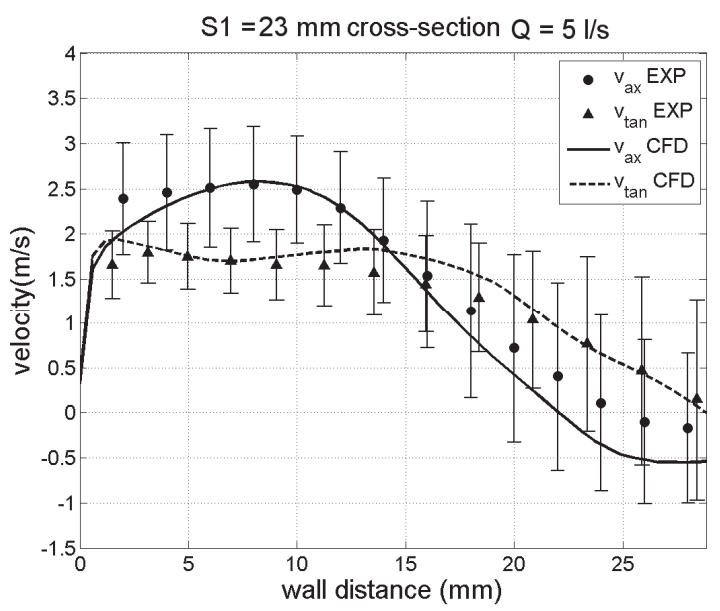

Figure 11. Measured (EXP) and computed (CFD) axial and tangential velocities for flow rate $\mathrm{Q}=5 \mathrm{l} / \mathrm{s}$ in $\mathrm{S} 1$ cross-section.

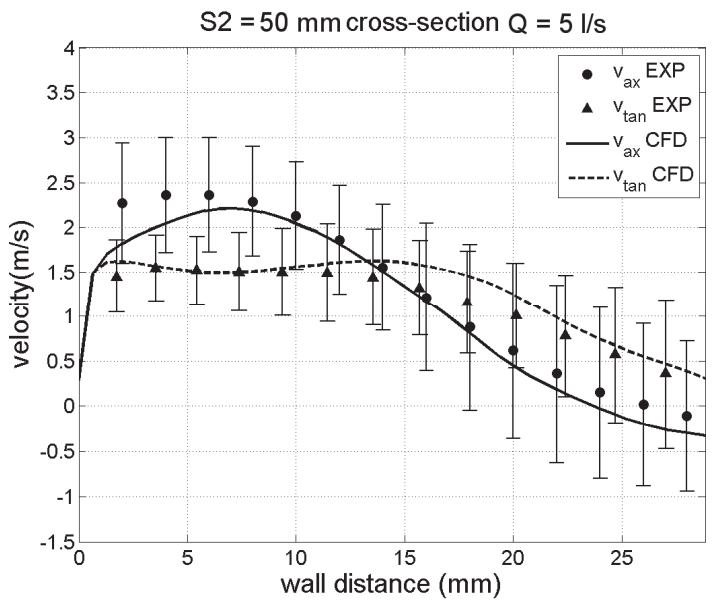

Figure 12. Measured (EXP) and computed (CFD) axial and tangential velocities for flow rate $Q=51 / s$ in $S 2$ cross-section.

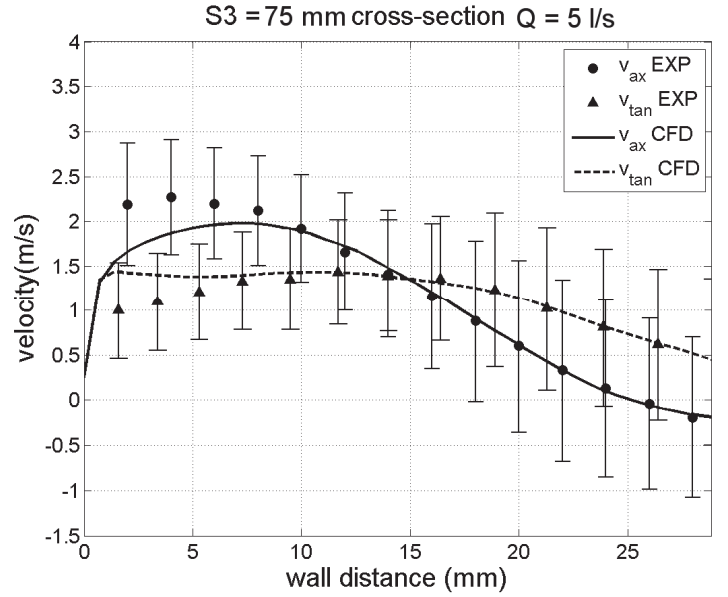

Figure 13. Measured (EXP) and computed (CFD) axial and tangential velocities for flow rate $Q=51 / s$ in $S 3$ cross-section.

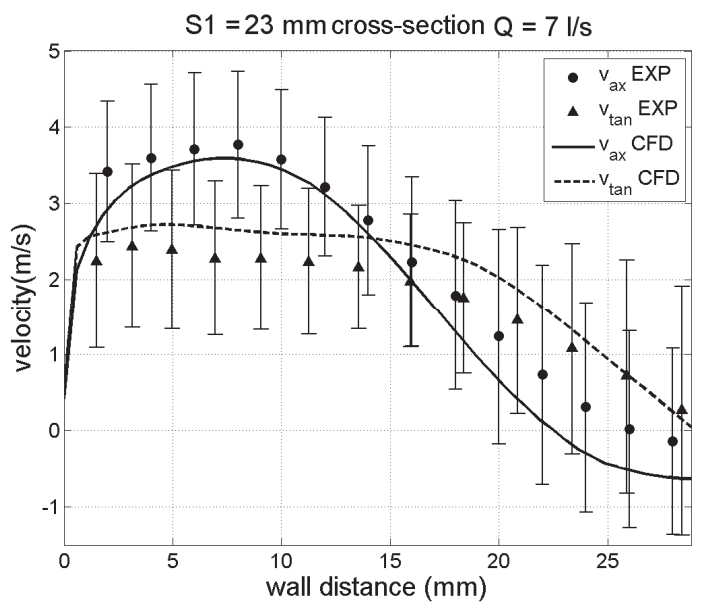

Figure 14. Measured (EXP) and computed (CFD) axial and tangential velocities for flow rate $\mathrm{Q}=7 \mathrm{l} / \mathrm{s}$ in $\mathrm{S} 1$ cross-section.

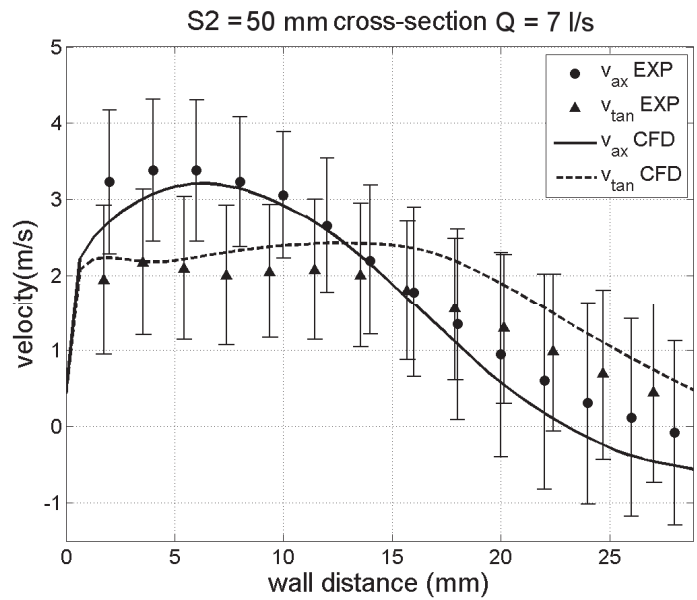

Figure 15. Measured (EXP) and computed (CFD) axial and tangential velocities for flow rate $\mathrm{Q}=7 \mathrm{l} / \mathrm{s}$ in $\mathrm{S} 2$ cross-section. 


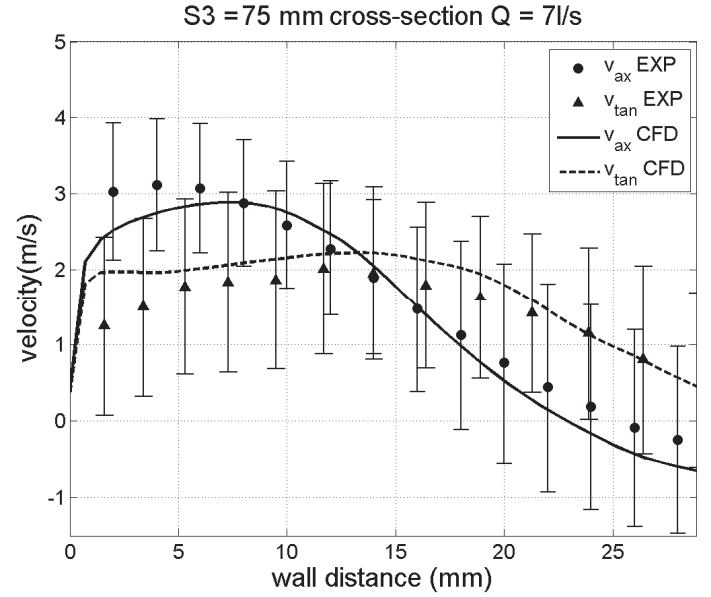

Figure 16. Measured (EXP) and computed (CFD) axial and tangential velocities for flow rate $\mathrm{Q}=7 \mathrm{l} / \mathrm{s}$ in $\mathrm{S} 3$ cross-section.

\section{Conclusions}

The swirling flow in a conical diffuser forming the spiral vortex structure was investigated.

The largest discrepancy between measured and computed velocities was found in the diffuser centre and close to the wall region. The largest inaccuracy in numerical model using RANS turbulence model is expected in wall region, where calculation suffers from boundary treatment by the wall functions. The standard nukWallFunction was used and in case of flow rate $Q=5$ $1 / \mathrm{s}$ the average value of $\mathrm{y}+=11$ (blade surface), 37 (central spike) and 45 (outer walls). On the other hand largest inaccuracies in LDA measurements are expected in the centre of the diffuser, where the mean velocity is close to zero and fluctuations are very large [9].

From computed velocity profiles for flow rate $Q=5$ $1 / \mathrm{s}$ it is clear that both, the central backflow region and magnitude of axial and tangential velocities decreases downstream through the investigated cross-sections. On the other hand for flow rate $Q=71 / \mathrm{s}$ the central back flow region stays almost unchanged while the magnitude of axial and tangential velocities decreases in region of main flow. The reason is that the vortex structure at flow rate $\mathrm{Q}=7 \mathrm{l} / \mathrm{s}$ is more developed than at $\mathrm{Q}=5 \mathrm{l} / \mathrm{s}$.

The calculation using open-source CFD software OpenFOAM and above mentioned case set-up show very good agreement with experimental measurements for both tested flow rates of $Q=5$ and $71 / \mathrm{s}$. Thus the numerical calculation can be used to adequately predict flow fields of entire range flow rates and especially higher flow rates $(\mathrm{Q}>11 \mathrm{l} / \mathrm{s})$ where the cavitating vortex structure appears and could causes laser beam reflection on the liquid/vapour interface during the LDA measurements.

\section{Acknowledgement}

This work is an output of research and scientific activities of NETME Centre, regional R\&D centre built with the financial support from the Operational Programme Research and Development for Innovations within the project NETME Centre (New Technologies for
Mechanical Engineering), Reg. No. CZ.1.05/2.1.00/01.0002 and, in the follow-up sustainability stage, supported through NETME CENTRE PLUS (LO1202) by financial means from the Ministry of Education, Youth and Sports under the „National Sustainability Programme I“

\section{References}

1. F.G. Novak, An Experimental Investigation of Vortex Breakdown in Tubes at High Reynolds Numbers. Dissertation thesis. (Naval Postgraduate School. Monterey, California 1998).

2. C. Brücker, Exp. in Fluids, 14, 133-139 (1993)

3. O. Lucca-Negro, T. O'Doherty, Progress in Energy and Combustion Science 27, 431-481 (2001)

4. P. Rudolf, Applied and Comp. Mech. 3, $177-184$ (2009)

5. F. Gallaire, M. Ruith, E. Meiburg, J.-M. Chomaz and P. Huerre, J. Fluid Mech. 549, 71-80 (2006)

6. R.-K. Zhang, Q.-D. Cai, J.-Z. Wu, Y.-L. Wu,S.-H. Liu and L. Zhang, Mod. Phys. Lett. B 19, 99-102 (2005)

7. R.F. Susan-Resiga, S. Muntean, H. Hasmatuchi, I. Anton, F. Avellan, J. Fluids Eng. 132 (2010)

8. P. Kanninen, Turbulence Modeling in Heat Transfer Applications (Postgraduate Seminar on omputational Fluid Mechanics, 2013)

9. Z. Zhang, LDA Application Methods: Laser Doppler Anemometry for Fluid Dynamics (Springer, 2010) 